\title{
Investigation on structural and photoluminescence properties of (Co, Al) Co-doped $\mathrm{SnO}_{2}$ nanoparticles
}

\author{
P. Venkateswara Reddy ${ }^{1}$, S. Venkatramana Reddy ${ }^{1 *}$, B. Sankara Reddy ${ }^{2}$, R. P. Vijayalakshmi ${ }^{1}$ \\ ${ }^{1}$ Department of Physics, Sri Venkateswara University, Tirupati-517 502, A.P., India \\ ${ }^{2}$ Visweswaraiah Institutes of Science and Technology, Angallu, Madana Palli, A.P., India \\ drsvreddy123@gmail.com
}

\begin{abstract}
Pure and $(\mathrm{Co}, \mathrm{Al})$ co-doped $(\mathrm{Co}=1,3,5 \mathrm{~mol} \%$, and $\mathrm{Al}=5 \mathrm{~mol} \%$ as constant $) \mathrm{SnO}_{2}$ nanoparticles were synthesized in aqueous solution by the chemical co-precipitation method using polyethylene glycol (PEG) as a stabilizer. The effects of structural and photoluminescence of (Co, $\mathrm{Al})$ co-doped $\mathrm{SnO}_{2}$ nanoparticles are investigated. The XRD pattern reveals that the samples are in a single phase rutile type tetragonal crystalline structure of $\mathrm{SnO}_{2}$. The peak positions with Co concentration are slightly shifted to lower $2 \theta$ values and size of particles from XRD calculations are in between $20-30 \mathrm{~nm}$. The Raman studies of the samples reveal that the Raman peaks are shifted towards lower wave numbers, when compared to those of pure $\mathrm{SnO}_{2}$ at $150 \mathrm{~cm}^{-1}, 303 \mathrm{~cm}^{-1}, 476 \mathrm{~cm}^{-1}, 630 \mathrm{~cm}^{-1}$, and $765 \mathrm{~cm}^{-1}$ respectively. Photoluminescence studies show that pure $\mathrm{SnO}_{2}$ has an emission peak at $444 \mathrm{~nm}$ and $(\mathrm{Co}, \mathrm{Al})$ co-doped samples show emission peaks at $417 \mathrm{~nm}, 433 \mathrm{~nm}$ and $485 \mathrm{~nm}$ with exciting wave length $320 \mathrm{~nm}$. The PL intensity increases and broadening of peaks for co-doped samples with increase of Co concentration indicates the decrease of size of the crystallinity. The UV absorption spectrum exhibits absorption at $310 \mathrm{~nm}$, and is in agreement with the emission spectra.
\end{abstract}

Keywords: EDAX, co-precipitation method, PL, UV-Absorption.

Received: 23 January 2016

\section{Introduction}

The importance for the synthesis of nanoparticles with desirable size and surface morphology has increased because of their potential applications in various fields in material sciences [1], electronics [2], and optics [3,4]. Tin oxide $\left(\mathrm{SnO}_{2}\right)$ is an n-type metal oxide semiconductor with a wide band gap (3.6 eV) [5-7]. As such, $\mathrm{SnO}_{2}$ offers wide range of applications in solar cells [8,9], catalytic support materials [10], transparent electrodes [11,12] and solid state chemical sensors [13-17]. Many efforts have been made to synthesize the $\mathrm{SnO}_{2}$ nanoparticles by sol-gel, chemical vapor deposition (CVD), thermal decomposition [18], co-precipitation [19], microwave assisted solution [20], and gas phase condensation [21] methods. Preparation of $\mathrm{SnO}_{2}$ nanoparticles at low cost on an industrial scale is a challenge in material production, and co-precipitation is a simple technique under suitable conditions of synthesis. High surface area with agglomeration and irregular particle morphology of $\mathrm{SnO}_{2}$ nano powders have been reported [22-24]. The preparation of desirable size of metal oxide nanoparticles using chemical coprecipitation method and their characterization are still challenging. Optical techniques, such as photoluminescence (PL), are very useful to determine the structure, defects and impurities in the nano crystals. Previous investigations have generated many reports on the luminescence of $\mathrm{SnO}_{2}$ nanocrystals [22-26]. The luminescence has been observed to range from $350-550 \mathrm{~nm}$ (UV and visible regions), which may be due to defects such as oxygen vacancies and tin interstitials or dangling bonds [27-31]. The generation of defects in nanocrystals varies with shape of nanocrystals, which would influence the emission properties. Feng Gu et. al. [32] have proposed a model for blue emission from $\mathrm{SnO}_{2}$ nanocrystals. The room temperature photoluminescence of blue emission with weak intensity has recently been reported by Zhijie Li [33]. Particle size plays a significant role in the optical properties the valence band. In order to overcome the stronger luminescence property with peak shift and to prepare $\mathrm{SnO}_{2}$ nanocrystalline powders with the desired size, the chemical co-precipitation method was chosen. In the present paper, a systematic study was undertaken to characterize the structure of nanocrystalline pure and (Co, Al) co-doped nanoparticles prepared by the chemical co-precipitation method. The photoluminescence properties and the results are also discussed.

\section{Synthesis}

$\mathrm{SnCl}_{2} \cdot 2 \mathrm{H}_{2} \mathrm{O}$, Co $(\mathrm{CHOOH}) .6 \mathrm{H}_{2} \mathrm{O}$ and $\mathrm{AlCl}_{3}$ are $\mathrm{AR}$ grade for the synthesis of $\mathrm{Sn}_{1-x} \mathrm{Co}_{x} \mathrm{Al}_{y} \mathrm{O}_{2}$ series. The required amount of $\mathrm{SnCl}_{2} \cdot 2 \mathrm{H}_{2} \mathrm{O}$ is dissolved in de-ionized water, and aqueous ammonia is added drop wise to the above solution to maintain ${ }_{P} \mathrm{H}=9$ under constant stirring. Then, under constant stirring, co-doped ions are added 
to the above solution. A light brown precipitate was obtained, and then $2 \mathrm{ml}$ of polyethylene glycol was added to stabilize the particle size. Finally, the obtained precipitate was washed with de-ionized water and filtered out separately. Thereafter, the precipitate was dried at $80{ }^{\circ} \mathrm{C}$. The dried powders were subsequently annealed at $600{ }^{\circ} \mathrm{C}$ for 4 hours, affording $(\mathrm{Co}, \mathrm{Al})$ co-doped $\mathrm{SnO}_{2}$ nanoparticles.

\subsection{Characterizations}

The prepared powders were carefully subjected to the following characterization studies. Powder XRD pattern was recorded on Bruker diffractometer within the $2 \theta$ range of 20 to $80^{\circ}$ using $\mathrm{CuK}_{\mathrm{O}}$ as $\mathrm{X}$-ray source $(\lambda=$ $1.53906 \AA$ ). The structure of pure and co-doped $\mathrm{SnO}_{2}$ were analyzed by Micro Raman Spectroscopy (LAB-RAM HR, HORIBA JOBIN-YVON Spectrophotometer). The optical properties were analyzed by UV-VIS diffusion reflectance Spectroscopy using CARY 5E UV-VIS-NIR Spectrophotometer in the wavelength range 200-2500 nm. The room temperature photoluminescence (PL) studies were carried out with a PL Spectrometer.

\section{Results and Discussion}

\subsection{X-RAY Diffraction studies}

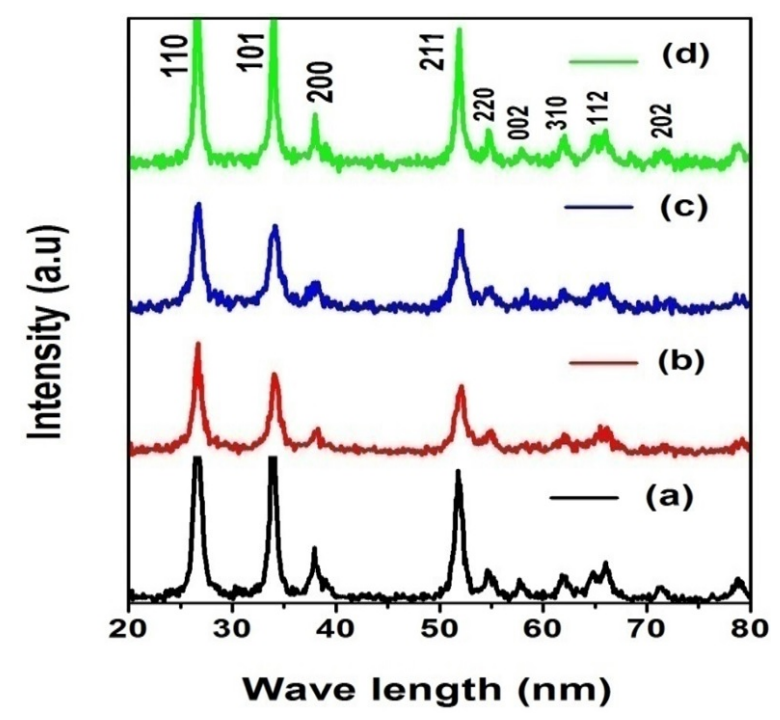

FIG. 1. XRD Spectra of (a) pure (b) $1 \mathrm{~mol} \% \mathrm{Co} \mathrm{(c)} 3 \mathrm{~mol} \% \mathrm{Co}$ (d) 5 mol \% Co with $5 \mathrm{~mol} \%$ $\mathrm{Al}$ co-doped $\mathrm{SnO}_{2}$ nanoparticles

Figure 1 shows the XRD pattern of pure and co-doped $(\mathrm{Co}=1,3,5 \mathrm{~mol} \%$ with $5 \mathrm{~mol} \% \mathrm{Al}$ as constant $) \mathrm{SnO}_{2}$ nanoparticles. The diffraction peaks of the samples corresponded to the rutile phase of $\mathrm{SnO}_{2}$, and peak positions are in good agreement with the standard pattern [JCPDS CARD No: 41-1445]. The absence of extra peaks showed that no impurity phases were present in samples within the detection limit of the instrument. However, it was found that the diffraction peaks of all co-doped samples were slightly shifted to lower positions when compared to the pure $\mathrm{SnO}_{2}$ nanoparticles. The crystallite size $(d)$ is calculated using Scherer formula:

$$
d=\frac{0.91 \lambda}{\beta \cos \theta}
$$

The calculated particle size for pure and $\mathrm{Co}(1,3,5 \mathrm{~mol} \%)$ with $5 \mathrm{~mol} \%$ of $\mathrm{Al}$ co-doped $\mathrm{SnO}_{2}$ nanoparticles were in between 20-30 nm. The diffraction calculations showed that the size of pure $\mathrm{SnO}_{2}$ particles was small and the size increased with the doping of Co with $5 \mathrm{~mol} \%$ of $\mathrm{Al}$ doped $\mathrm{SnO}_{2}$.

\subsection{Raman studies}

Figure 2 shows the Raman spectrum of synthesized nano crystals. In the present investigation, for pure $\mathrm{SnO}_{2}$, exhibit peaks were observed at $476 \mathrm{~cm}^{-1}, 630 \mathrm{~cm}^{-1}$ and $776 \mathrm{~cm}^{-1}$ which corresponded to $\mathrm{E}_{g}, \mathrm{~A}_{1 g}$ and $\mathrm{B}_{2 g}$ respectively. The Raman peaks of $\mathrm{Co}(1,3,5 \mathrm{~mol} \%)$ with $5 \mathrm{~mol} \%$ of $\mathrm{Al}$ to $\mathrm{SnO}_{2}$ nanoparticles at $150 \mathrm{~cm}^{-1}$, $303 \mathrm{~cm}^{-1}, 476 \mathrm{~cm}^{-1}, 630 \mathrm{~cm}^{-1} 692 \mathrm{~cm}^{-1}$, and $765 \mathrm{~cm}^{-1}$ and. They correspond to $\mathrm{B}_{1 g}, \mathrm{E}_{u}, \mathrm{E}_{g}, \mathrm{~A}_{1 g}, \mathrm{~A}_{2 u} \mathrm{LO}$ (LO: mode of longitudinal optical phonons), and $\mathrm{B}_{2 g}$ respectively. The peak at $856 \mathrm{~nm}$ is might be laser peak. 


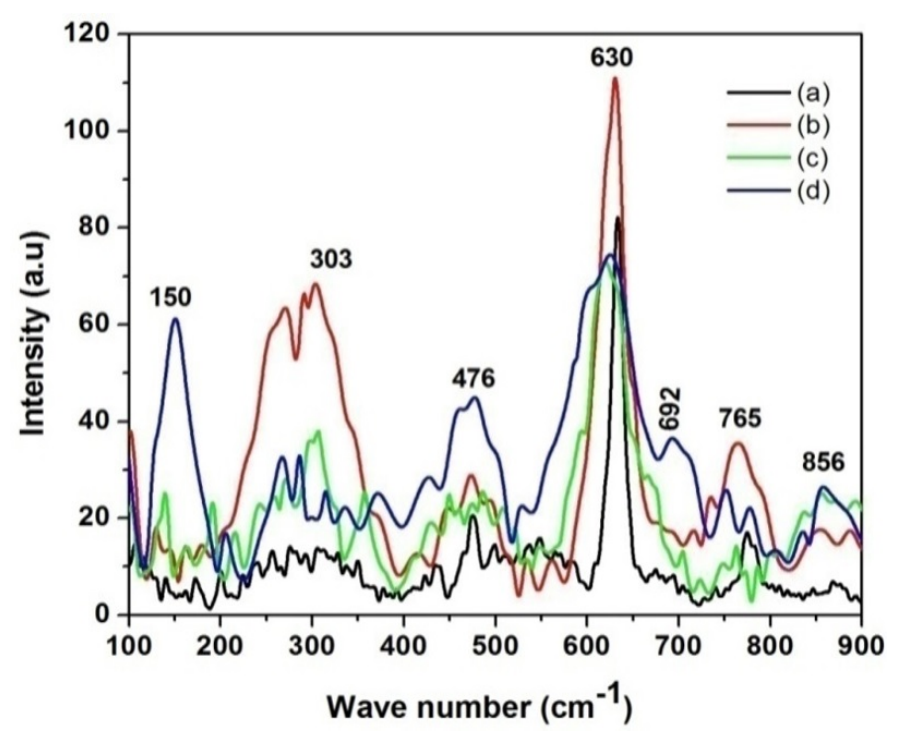

FIG. 2. Raman Spectra of (a) pure (b) 1 mol \% Co (c) 3 mol \% Co (d) 5 mol \% Co, with 5 mol \% of $\mathrm{Al}$ co-doped $\mathrm{SnO}_{2}$ nanoparticles

The co-doped peaks are broad and slightly shifted to lower wave numbers as compared to bulk rutile $\mathrm{SnO}_{2}$. The sharp band located between $550-650 \mathrm{~cm}^{-1}$ is attributed to the surface vibration modes [34]. The origin of peaks at $303 \mathrm{~cm}^{-1}$ may be due to $\mathrm{E}_{u}$ mode and peak at $476 \mathrm{~cm}^{-1}$ represents the Raman active $\mathrm{E}_{g}$ doubly degenerate mode. The $\mathrm{A}_{1 g}$ and $\mathrm{B}_{2 g}$ are non-degenerate modes at $630 \mathrm{~cm}^{-1}$ and $765 \mathrm{~cm}^{-1}$ respectively.

\subsection{Photoluminescence analysis}

The PL emission peaks for pure $\mathrm{SnO}_{2}$ nanoparticles were at $417 \mathrm{~nm}$ and $456 \mathrm{~nm}$ and for co-doped samples the peaks were at $417 \mathrm{~nm}, 433 \mathrm{~nm}$, and $485 \mathrm{~nm}$ when the excitation wavelength was $320 \mathrm{~nm}$. The spectrum was characteristic of the UV emissions at $417 \mathrm{~nm}$, and $433 \mathrm{~nm}$. The peak at $485 \mathrm{~nm}$ indicates blue emission, which was due to the reduced nanocrystal sizes and intrinsic defects in lattice of $\mathrm{SnO}_{2}$. With an increase in the Co concentration, the oxygen vacancies increased, which resulted in the broadening of the peaks along with increased peak intensity. This might be due to the electron transitions mediated by defect levels in the band gap and also due to the non-uniformity of the particle size [35].

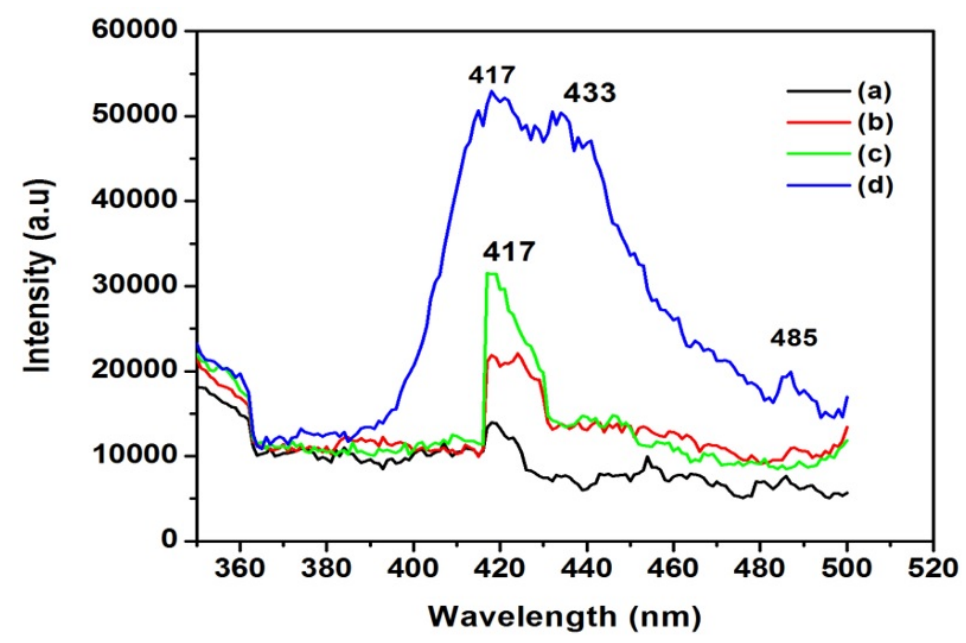

FIG. 3. PL spectra of (a) pure (b) $1 \mathrm{~mol} \% \mathrm{Co}$, (c) $3 \mathrm{~mol} \% \mathrm{Co}$ (d) $5 \mathrm{~mol} \%$ Co with $5 \mathrm{~mol} \%$ Al co-doped $\mathrm{SnO}_{2}$ nanoparticles 


\subsection{UV-VIS Absorption}

Absorption spectroscopy is a powerful non destructive technique used to investigate the optical properties of semiconducting nanoparticles. The optical absorption spectra of $(\mathrm{Co}, \mathrm{al})$ co-doped $\mathrm{SnO}_{2}$ nanoparticles are shown in Fig. 4. The absorption spectra showed an absorption edge at $\sim 310 \mathrm{~nm}$, and for different samples the value is almost identical. It is interesting to note that $(\mathrm{Mn}, \mathrm{Al})$ doped samples do not show a sharp absorption edge due to Mn d states extending in to the band gap region resulting from the overlapping of orbitals by Mandal et al [36]. The changes in local disorder result from the varying crystalline size and annealing temperature of the samples.

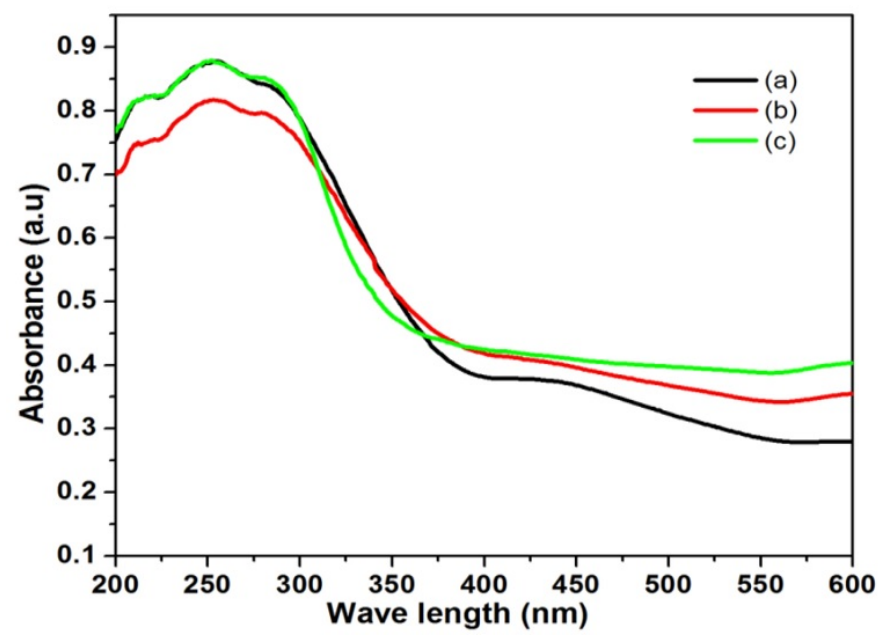

FIG. 4. UV-Absorption Spectra of (a) $1 \mathrm{~mol} \%$ Co (b) $3 \mathrm{~mol} \%$ Co (c) $5 \mathrm{~mol} \%$ Co co-doped with $5 \% \mathrm{Al}$ into $\mathrm{SnO}_{2}$ nanoparticles

\section{Summary and conclusion}

In summary, tin oxide $\left(\mathrm{SnO}_{2}\right)$ nanocrystalline powders were successfully synthesized by a simple precipitation method obtained at $600^{\circ} \mathrm{C}$ by a reaction of $\mathrm{SnCl}_{2}$ and $\mathrm{NH} 3$ derived from aqueous ammonia. The XRD patterns confirm that $\mathrm{SnO}_{2}$ nanocrystalline powders possess a tetragonal rutile structure. The average crystallite size of the nanopowders is in the nanometer range; the crystallite size of the $\mathrm{SnO}_{2}$ was found to increase from 20 to $30 \mathrm{~nm}$. The heating effect has influence on the size of the crystallites in the nanocrystalline powders. When samples were heated, the lattice parameters and dislocation density decreased, and thus, a smaller number of unit cells started to grow. The Photoluminescence emission exhibited peaks at $417 \mathrm{~nm}, 433 \mathrm{~nm}$ and $485 \mathrm{~nm}$. The peak at $417 \mathrm{~nm}$ is related to the recombination of electrons in singly occupied oxygen vacancies with photo-excited holes in the valence band. The heating temperature also affects the luminescence process, the emission resulting in the decrease in the oxygen vacancies, as revealed by the decrease in luminescence at $485 \mathrm{~nm}$. This is in agreement with the absorption edge at $310 \mathrm{~nm}$.

\section{Acknowledgement}

The authors wish to express their gratitude to Prof. Y. Prabhakara Reddy (Retd.), Department of Physics, S. V. University, Tirupati for his critical discussions during the course of investigation.

\section{References}

[1] Gudiksen M.S., Lauhon L.J., Wang J., Smith D., Lieber C.M. Nature, 2002, 415, P. 617.

[2] Wang Z.L., Song J.H. Science, 2006, 312, P. 242.

[3] Sun X.M., Li Y.D. Angew. Chem., Int. Ed., 2004, 43, P. 3827.

[4] Tang Z.Y., Wang Y., Shanbhag S., Giersig M., Kotov N.A. J. Am. Chem. Soc., 2006, 128, P. 6730.

[5] Kar A., Patra A. J. Phys. Chem C, 2009, 113, P. 4375.

[6] Xu X., Zhuang J., Wang X. J. Am. Chem. Soc., 2008, 130, P. 12527.

[7] Lu E.J.H., Ribeiro C., Giraldi T.R., Longo E., Leite E.R., Varela J.A. Appl. Phys. Lett., 2004, 84, P. 1745.

[8] Harrison P.G., Willet M.J. Nature, 1988, 332, P. 337.

[9] Ferrere S., Zaban A., Gregg B.A. J. Phys. Chem B, 1997, 101, P. 4490.

[10] Wang W.W., Zhu Y.J., Yang L.X. AdV. Funct. Mater., 2007, 17, P. 50.

[11] Zhu J., Lu Z., Aruna S. T., Aurbach D., Gedanken A. Chem. Mater, 2000, 12, P. 2557. 
[12] He Y.S., Campbell J.C., Murphy R.C., Arendt M.F., Swinnea J.S. J. Mater. Res., 1993, 8, P. 3131.

[13] Wang Y., Jiang X., Xia Y. J. Am. Chem. Soc., 2003, 125, P. 16176.

[14] Xi G., Ye J. Inorg. Chem., 2010, 49, P. 2302.

[15] Chen Y.J., Xue X.Y., Wang Y.G., Wang T.H. Appl. Phys. Lett., 2005, 87, P. 233503.

[16] Liu Z., Zhang D., Han S., Li C., Tang T., Jin W., Liu X., C. AdV. Mater, 2003, 15, P. 1754.

[17] Kolmakov A., Klenov D.O., Lilach Y., Stemmer S., Moskouits M. Nano Lett., 2005, 5, P. 667.

[18] Liu Y., Dong J., Liu M. Adv. Mater, 2004, 16, P. 353.

[19] Ki Chang Song, Yong Kang, Materials Letters, 2000, 42, P. 283.

[20] H. Hallila, P. Méninia, H. Auberta. Procedia Chemistry, 2009, 1, P. 935.

[21] Zhang J., Gao L. Chem. Lett., 2003, 32, P. 458.

[22] Gu F., Wang S.F., Lu“ M.K., Zhou G.J., Xu D., Yuan D.R. J. Phys. Chem B, 2004, 108, P. 8119.

[23] Chowdhury P.S., Saha S., Patra A. Solid State Commun., 2004, 131, P. 785.

[24] Faglia G., Baratto C., Sberveglieri G., Zha M., Zappeltini A. Appl. Phys. Lett., 2005, 86, P. 011923.

[25] Maestre D., Cremades A., Piqueras J. J. Appl. Phys., 2005, 97, P. 044316.

[26] Gu F., Wang S.F., Song C.F., Lu“ M.K., Qi Y.X., Zhou G.J., Xu D., Yuan D.R. Chem. Phys. Lett., 2003, 372, P. 451.

[27] Munnix S., Schmeits M. Phys. ReV. B, 1983, 27, P. 7624.

[28] Chiodini N., Paleari A., Dimartino D., Spinolo G. Appl. Phys. Lett., 2002, 81, P. 1702.

[29] Vanheusden K., Warren W.L., Seager C.H., Tallant D.R., Voigt J.A., Gnade B.E. J. Appl. Phys., 1996, 79, P. 7983.

[30] Liu Y.X., Yang Q.B., Xu C.F. J. Appl. Phys.,2008, 104, P. 064701.

[31] Godinho K.G., Walsh A., Watson G.W. J. Phys. Chem. C, 2009, 113, P. 439.

[32] Gu F., Wang S.F., Lu“ M.K., Zhou G.J., Xu D., Yuan D.R. J. Phys. Chem B, 2004, 108, P. 8119.

[33] Zhijie Li, Wenzhong Shen, Xue Zhang, Limei Fang, Xiaotao Zu. Colloids and surfaces A: Physicochem. Eng. Aspects, 2008, 327 , P. 17.

[34] Abello L., Bochu B., Gaskov A., Koudryavtseva S., Lucazeau G., and Rumyantseva, M. Structural characterization of nanocrystalline $\mathrm{SnO}_{2}$ by X-Ray and Raman Spectroscopy. J.Solid State Chem., 1998, 135, P. 78-85.

[35] Fang L.M., Zu X.T., Li Z.J., Zhu S., Liu C.M., Wang L.M., Gao F., Microstructure and luminescence properties of Co-doped $\mathrm{SnO}_{2}$ nanoparticles synthesized by hydrothermal method. J. Mater. Sci.: Mater. Electron, 2008, 19, P. 868-874.

[36] Mandal S.K., Nath T.K., Das A. J. Appl. Phys., 2007, 101, P. 123920. 